\title{
Ecology of Indigenous Lactic Acid Bacteria along Different Winemaking Processes of Tempranillo Red Wine from La Rioja (Spain)
}

\author{
Lucía González-Arenzana, Pilar Santamaría, Rosa López, Carmen Tenorio, \\ and Isabel López-Alfaro \\ Instituto de Ciencias de la Vid y del Vino (ICVV), CSIC, Universidad de La Rioja, Gobierno de La Rioja, C/Madre de Dios 51, \\ La Rioja, 26006 Logroño, Spain
}

Correspondence should be addressed to Isabel López-Alfaro, ilopezalfaro@yahoo.es

Received 2 November 2011; Accepted 5 December 2011

Academic Editors: E. Garcia-Moruno and Z.-X. Quan

Copyright (C) 2012 Lucía González-Arenzana et al. This is an open access article distributed under the Creative Commons Attribution License, which permits unrestricted use, distribution, and reproduction in any medium, provided the original work is properly cited.

Ecology of the lactic acid bacteria (LAB) during alcoholic fermentation (AF) and spontaneous malolactic fermentation (MLF) of Tempranillo wines from four wineries of La Rioja has been studied analyzing the influence of the winemaking method, processing conditions, and geographical origin. Five different LAB species were isolated during AF, while, during MLF, only Oenococcus oeni was detected. Although the clonal diversity of O. oeni strains was moderate, mixed populations were observed, becoming at least one strain with distinct PFGE profile the main responsible for MLF. Neither the winemaking method nor the cellar situation was correlated with the LAB diversity. However, processing conditions influenced the total number of isolates and the percentage of each isolated species and strains. The winemaking method could cause that genotypes found in semicarbonic maceration did not appear in other wineries. Four genotypes of O. oeni were isolated in more than one of the rest wineries. These four together with other dominant strains might be included in a future selection process.

\section{Introduction}

Winemaking is defined like the operations and the practises carried out to transform the grapes in wine [1]. This includes two fermentative stages, which are the alcoholic fermentation (AF) led by yeast and the malolactic fermentation (MLF) performed by lactic acid bacteria (LAB). The MLF is not a real fermentation, it mainly consists in a transformation of Lmalic acid into L-lactic acid and carbon dioxide, as a part of the LAB metabolism [2], and it contributes to improve the stability and the quality of the final wine [3-5]. The positive effects of MLF in wine depend on the control of the process conditions. Oenococcus oeni is the best adapted LAB species to the stressful environment in wine $[6,7]$ so it is the species which is mostly isolated at this stage [8], being the main responsible for the development of MLF and the most interesting to be selected [9]. In order to get a better control of MLF and to avoid wine spoilage $[10,11]$, wineries have started to employ commercial cultures from selected O. oeni strains. However, not always these malolactic starters are successfully implanted [12]. Several reports have shown that the success of these starters depends on strain and is influenced by several factors, including geographical origin [13] and adaptation to the winemaking conditions of each wine [14-18]. Therefore, it is recommended to study the representative and best-adapted microbiota to the type of wine and the winemaking procedures in each elaboration area. Some authors have conducted studies about ecology of LAB in wineries, but none of them have analyzed more than one winery both at the same vintage in AF and MLF and in the Appellation of Origin Rioja [19, 20]. The main aim of this paper was to analyze the LAB species diversity and the intraspecific diversity of $O$. oeni, studying the geographical distribution at different subzones of this region of the north of Spain. In addition, more relevant correlations between LAB diversity and winemaking process were investigated. 


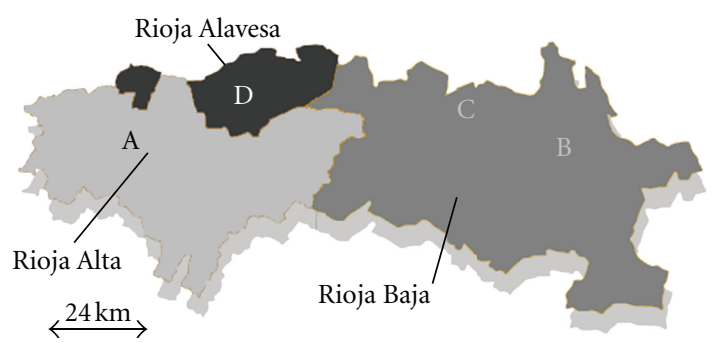

Figure 1: Location of the four wineries in the three subzones of the Appellation of Origin Rioja.

\section{Materials and Methods}

2.1. Samples of Musts and Wines. Samples of Tempranillo red wine were taken from four wineries located in three different subzones of Appellation of Origin Rioja (Figure 1). None of the surveyed wineries had ever used LAB commercial starter cultures. The AF was carried out by the destemming and crushing method in stainless-steel tanks, except in the case of winery $\mathrm{D}$ which was carried out by the traditional semicarbonic maceration method (whole grape) in open cement tanks.

When AF was completed, wines were racked and placed in stainless-steel tanks in the case of wineries A, B, and C and in open cement tank for winery $D$. The wines underwent spontaneous MLF with the endogenous microbiota (no starter inocula was used).

One fermentation tank was sampled in each winery. Wine samples were taken aseptically for chemical and microbiological analysis at different times: must (stage 1), tumultuous AF (density around 1,025; stage 2), at the end of AF $(<2$ g/L glucose + fructose; stage 3 ), initial MLF (consumption of $10 \%$ of the initial malic acid; stage 4 ), tumultuous MLF (consumption of $60 \%$ of the initial malic acid; stage 5), and at the end of MLF ( $\mathrm{L}-$ malic acid concentration $<0.5 \mathrm{~g} / \mathrm{L}$; stage 6$)$. Wineries A and B were only sampled after the end of AF.

2.2. Chemical Analysis. Alcohol degree, $\mathrm{pH}$, total acidity, volatile acidity, reducing sugars, free and total sulphur dioxide $\left(\mathrm{SO}_{2}\right)$, tonality, and colour intensity were measured according to the European Community Official Methods [21]. Histamine was analyzed by reverse-phase HPLC using the method reported by López et al. [22]. MLF was followed by measuring wine L-malic and L-lactic acid content by enzymatic methods [21] (Enzymatic BioAnalysis, BoehringerMannheim/R-Biopharm, Germany).

2.3. Bacterial Enumeration and Isolation. Samples were diluted in sterile saline solution and plated on MRS agar (Scharlau Chemie S.A., Barcelona, Spain) plates supplemented with tomato juice $(10 \% \mathrm{v} / \mathrm{v})$, fructose $(6 \mathrm{~g} / \mathrm{L})$, cysteine-HCl $(0.5 \mathrm{~g} / \mathrm{L})$, L-malic acid $(5 \mathrm{~g} / \mathrm{L})$, and $50 \mathrm{mg} / \mathrm{L}$ of pymaricine (Acofarma, S. Coop., Spain). Plates were incubated at $30^{\circ} \mathrm{C}$ under strict anaerobic conditions (Gas Pak System, Oxoid Ltd., Basingstoke, England) for at least ten days, and viable counts were reported as the number of
$\mathrm{CFU} / \mathrm{mL}$. Fifteen colonies from each wine sample were selected for reisolation and identification. Isolates were stored in $20 \%$ sterile skim milk (Difco) at $-20^{\circ} \mathrm{C}$.

2.4. Species Identification. Species identification was carried out by previously recommended methods, which included bacteria morphology, Gram staining, and catalase reaction [23]. In order to get a better and more precise identification, molecular biology methods were used. Oenococcus oeni, Lactobacillus plantarum, and Lactobacillus brevis species were confirmed by the species-specific PCR method [24, 25]. In case of identification of other unknown species, PCR amplification of partial 16S rRNA genes was performed with WLAB1 and WLAB2 as previously described López et al. [26]. PCR products were sequenced by Macrogen Inc. (Seoul, Republic of Korea), and sequences were used for comparison to the data in GenBank using the Basic Local Alignment Search Tool (BLAST) [27].

2.5. Strain Typing of O. oeni. PFGE was carried out according to the method described by Birren and Lai [28], with some modifications [8] for agarose block preparation. Macrorestriction analysis was performed with two endonucleases, first with SfiI following the method reported by López et al. [8] and then with ApaI by the method reported by Larisika et al. [29], with modifications for optimal separation of fragments: $1.2 \%(\mathrm{w} / \mathrm{v})$ agarose gels were submitted to $24 \mathrm{~h}$ with a pulse ramping between 0.5 and $20 \mathrm{~s}$ at $14^{\circ} \mathrm{C}$ and $6 \mathrm{~V} / \mathrm{cm}$ in a CHEF DRII apparatus (Bio-Rad).

2.6. Numerical Analysis of Gel Images. The conversion, normalization, and further processing of images were carried out by FPQuest software version 5.1 (Bio-Rad, USA). Comparison of the obtained PFGE patterns were made by Pearson correlation coefficient and with Unweighted Pair Group Method using Arithmetic Averages (UPGMA).

\section{Results and Discussion}

Results for analytical composition of wines in the four studied cellars are displayed in Table 1. Data were within the range of Tempranillo wines from this Spanish region [22]. In all the wineries, volatile acidity underwent a light increase after MLF as expected, and, in any case, it was important to the final quality of the wine. The wine colour intensity and total phenols decreased after MLF, and the tonality increased slightly in all the wineries. Histamine in wines increased during MLF, but its concentration was low in all the studied wines, except in winery A. Different factors usually affect the biogenic amine formation [30]; the main is the presence of free amino acid and microorganisms able to decarboxylate them. This ability is highly variable, and it depends not only on the species but also on the strain and on the environmental conditions [31].

Figure 2 shows the evolution of the viable LAB population and the L-malic acid decrease during the fermentation period. In every situation, an increase in LAB population was related to decrease levels of L-malic acid. The AF in wineries 
TABLE 1: Analytical composition of wines at final AF (stage 3) and final MLF (stage 6) in each winery.

\begin{tabular}{|c|c|c|c|c|c|c|c|c|}
\hline \multirow{2}{*}{$\begin{array}{l}\text { Winery } \\
\text { Stage }\end{array}$} & \multicolumn{2}{|c|}{ A } & \multicolumn{2}{|c|}{ B } & \multicolumn{2}{|c|}{$\mathrm{C}$} & \multicolumn{2}{|c|}{$\mathrm{D}$} \\
\hline & 3 & 6 & 3 & 6 & 3 & 6 & 3 & 6 \\
\hline Alcohol content $(\% \mathrm{v} / \mathrm{v})$ & 12.9 & - & 13.4 & - & 14.0 & - & 12.4 & - \\
\hline $\mathrm{pH}$ & 3.56 & 3.73 & 3.50 & 3.59 & 3.32 & 3.50 & 3.61 & 3.86 \\
\hline Total acidity (g/L tartaric acid) & 7.69 & 5.81 & 7.72 & 6.63 & 9.00 & 7.20 & 5.62 & 5.49 \\
\hline Volatile acidity (g/L acetic acid) & 0.22 & 0.40 & 0.33 & 0.45 & 0.26 & 0.37 & 0.16 & 0.30 \\
\hline L-malic acid (g/L) & 3.02 & 0.05 & 1.97 & 0.19 & 2.61 & 0.21 & 2.44 & 0.05 \\
\hline L-lactic acid (g/L) & - & 1.40 & - & 1.21 & - & 1.72 & - & 1.76 \\
\hline Free $\mathrm{SO}_{2}(\mathrm{mg} / \mathrm{L})$ & 14.5 & - & 17.0 & - & 13.2 & - & 29.8 & - \\
\hline Total $\mathrm{SO}_{2}(\mathrm{mg} / \mathrm{L})$ & 31.6 & - & 44.4 & - & 31.6 & - & 47.6 & - \\
\hline Total phenols (OD $280 \mathrm{~nm})$ & 53.2 & 48.8 & 66.1 & 53.1 & 71.3 & 67.0 & 63.5 & 57.9 \\
\hline Colour intensity $(\mathrm{OD}[420+520+620] \mathrm{nm})$ & 13.5 & 8.30 & 20.1 & 10.1 & 29.1 & 27.8 & 15.0 & 10.2 \\
\hline Tonality (OD 420/520 nm) & 0.44 & 0.60 & 0.41 & 0.57 & 0.34 & 1.26 & 0.40 & 0.54 \\
\hline Histamine (mg/L) & 0.00 & 6.52 & 0.00 & 3.39 & 0.00 & 0.33 & 0.00 & 0.33 \\
\hline
\end{tabular}

(-) not analyzed.

TABLE 2: Percentage of the LAB species at each stage of the vinification in the four studied wineries.

\begin{tabular}{lccccccccccccccccccc}
\hline Winery & \multicolumn{3}{c}{$\mathrm{A}$} & \multicolumn{3}{c}{$\mathrm{B}$} & \multicolumn{1}{c}{ C } & \multicolumn{1}{c}{ C } \\
Stage* & 4 & 5 & 6 & 4 & 5 & 6 & 1 & 2 & 3 & 4 & 5 & 6 & 1 & 2 & 3 & 4 & 5 & 6 \\
\hline O. oeni & 100 & 100 & 100 & - & 100 & 100 & 100 & 77 & 100 & 100 & 100 & 100 & - & - & 33 & 100 & 100 & 100 \\
L. plantarum & - & - & - & 36 & - & - & - & 8 & - & - & - & - & - & 50 & - & - & - & - \\
L. mali & - & - & - & 50 & - & - & - & 15 & - & - & - & - & - & - & - & - & - & - \\
Ln. mesenteroides & - & - & - & 7 & - & - & - & - & - & - & - & - & - & 50 & - & - & - & - \\
Lactobacillus sp. & - & - & - & 7 & - & - & - & - & - & - & - & - & - & - & 67 & - & - & - \\
\hline
\end{tabular}

*1: must; 2: tumultuous AF; 3: final AF; 4: initial MLF; 5: tumultuous MLF; 6: final MLF.

(-) not detected.

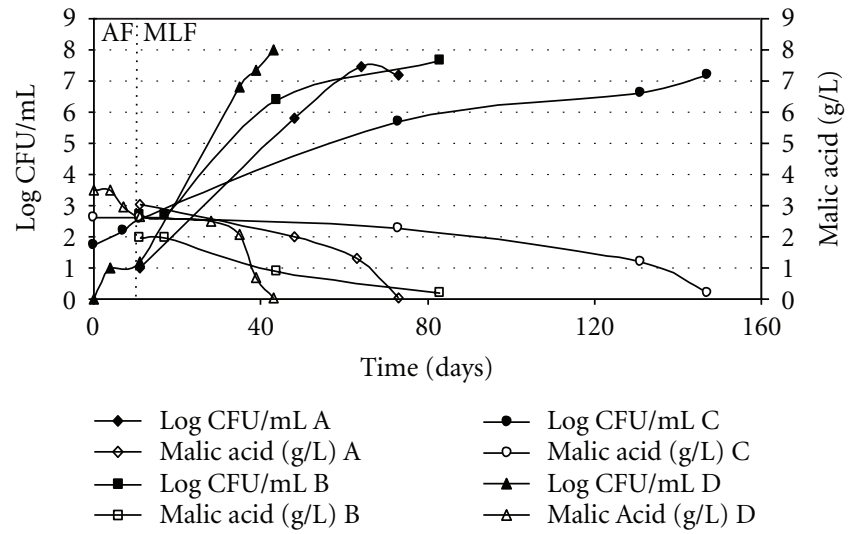

FIGURE 2: Viable LAB population and L-malic acid concentration in winemaking.

$\mathrm{C}$ and $\mathrm{D}$ was developed in 11 days. The MLF had variable duration ranged between 32 days in cellar $\mathrm{D}$ and 136 days in cellar $\mathrm{C}$; this longer fermentation was probably due to the lower $\mathrm{pH}$ and lower temperatures of the wine at the end of $\mathrm{AF}$ in this winery. In spite of the low temperatures, this winer$y$ did not use a control temperature method during MLF, what could produce longer latent period $[9,14,32,33]$. The $\mathrm{LAB}$ viable populations were in the range of $1.5 \times 10^{1}-$ $1.4 \times 10^{3} \mathrm{CFU} / \mathrm{mL}$ at the end of $\mathrm{AF}$ and $1.4 \times 10^{6}-3 \times$
$10^{7} \mathrm{CFU} / \mathrm{mL}$ at the end of MLF, similar to other spontaneous MLF $[20,34]$.

Table 2 shows the percentage of LAB species identified at each fermentative stage in every sampled winery. The highest species richness was detected in winery B in which five different LAB species were identified. O. oeni was not isolated at stage 4 in this winery, what could be caused as the MLF had not actually begun as it was indicated by the viable LAB count at this stage (Figure 2). Three and four LAB species were, respectively, found in cellars C and D, while in A only O. oeni was isolated.

Data of species distribution along winemaking showed that highest number of LAB species was observed during AF. In wineries $A$ and $\mathrm{C}, \mathrm{O}$. oeni became the main LAB isolated by the end of AF and it was the only one during MLF; these results have already been reported by other authors $[13,15,29,33]$ which highlighted the enormous adaptation of O. oeni to the strict wine conditions $[16,20]$.

Apparently, neither the type of winemaking nor the cellar situation was correlated with the diversity of LAB species in each cellar. However, processing conditions in each winery could influence the total number of isolates and the percentage of each isolated species. Thus, higher $\mathrm{SO}_{2}$ levels in AF could favour the growth of more resistant species to this antiseptic [35] (wineries B and D) and lower $\mathrm{pH}$ could promote the O. oeni development [32] (winery C). 
TABLE 3: Number of isolates and genotypes of O. oeni and index of diversity (ID*) during AF and MLF.

\begin{tabular}{lcccccc}
\hline Winery & A & B & \multicolumn{2}{c}{ C } & \multicolumn{2}{c}{ D } \\
Stages & MLF & MLF & AF & MLF & AF & MLF \\
\hline $\mathrm{N}^{\circ}$ of total isolates & 31 & 44 & 29 & 45 & 5 & 45 \\
$\mathrm{~N}^{\circ}$ of O. oeni isolates & 31 & 30 & 26 & 45 & 1 & 45 \\
$\mathrm{~N}^{\circ}$ of O. oeni genotypes & 8 & 5 & 9 & 7 & 1 & 5 \\
$\mathrm{ID}^{*}$ & 0.65 & 0.66 & 0.84 & 0.49 & - & 0.65 \\
\hline
\end{tabular}

${ }^{*} \mathrm{ID}=1-[1 / N(N-1)] \sum n_{\mathrm{j}}\left(n_{\mathrm{j}}-1\right)$, where the number of strains is $N$, and $n$ is the strains belonging to type " $\mathrm{j}$."

(-) incalculable.

TABLE 4: O. oeni genotypes, isolation stage, and frequency ${ }^{\mathrm{a}}(\%)$ of their appearance in each winery.

\begin{tabular}{|c|c|c|c|c|c|}
\hline \multirow{2}{*}{ Genotypes } & \multirow{2}{*}{ Isolation stage ${ }^{\mathrm{b}}$} & \multicolumn{4}{|c|}{ Wineries } \\
\hline & & $\mathrm{A}$ & B & $\mathrm{C}$ & $\mathrm{D}$ \\
\hline 1 & 5 & 10 & & & \\
\hline 2 & 6 & 3 & & & \\
\hline 3 & $4-5-6$ & 10 & & 3 & \\
\hline 4 & 6 & 3 & & & \\
\hline 5 & $4-5-6$ & 55 & & & \\
\hline 6 & 6 & 3 & & & \\
\hline 7 & 6 & 3 & & & \\
\hline 8 & 5 & & 15 & & \\
\hline 9 & 5 & & 6 & & \\
\hline 10 & $3-4-5-6$ & 13 & 41 & 14 & \\
\hline 11 & $3-6$ & & 29 & 4 & \\
\hline 12 & $4-5-6$ & & 9 & 45 & \\
\hline 13 & 1 & & & 1 & \\
\hline 14 & 2 & & & 1 & \\
\hline 15 & 2 & & & 6 & \\
\hline 16 & 2 & & & 1 & \\
\hline 17 & 2 & & & 4 & \\
\hline 18 & 3 & & & 1 & \\
\hline 19 & 3 & & & 4 & \\
\hline 20 & $4-6$ & & & 4 & \\
\hline 21 & 6 & & & 1 & \\
\hline 22 & $5-6$ & & & 4 & \\
\hline 23 & 6 & & & 4 & \\
\hline 24 & $3-4-5-6$ & & & & 20 \\
\hline 25 & $4-5-6$ & & & & 26 \\
\hline 26 & $4-5-6$ & & & & 50 \\
\hline 27 & 5 & & & & 2 \\
\hline 28 & 6 & & & & 2 \\
\hline
\end{tabular}

${ }^{a} \%$ Appearance $=n^{\circ}$ strains with a specific PFGE pattern $\times 100 /$ total $n^{\circ}$ of isolates per winery.

${ }^{\mathrm{b}}$ 1: must; 2: tumultuous AF; 3: final AF; 4: initial MLF; 5: tumultuous MLF; 6: final MLF.

Information relating to $O$. oeni typing is covered in Table 3. After subjecting the 182 O. oeni isolates to PFGE with Sfi endonuclease, twenty-eight different genotypes were detected (data not shown). Analysis with a second enzyme (ApaI) did not increase the number of differentiated patterns. Wineries $\mathrm{B}$ and $\mathrm{D}$ showed five distinct patterns for each one, A showed eight, and C fifteen. To our knowledge few studies of $O$. oeni strain variability during both AF and MLF have been reported so far. After comparing strain diversity between wineries, similar and moderate indexes of diversity (ID) [36] were observed in wineries $A, B$, and D in MLF. No correlation between geographical situation and strain diversity was observed as has been reported to yeast by Santamaría Aquilúe [37]. However, the vinification conkditions could have greatly influenced strain diversity. Thus, winery $\mathrm{C}$ showed a higher ID in AF which decreased considerably in MLF. This decrease could be due to the lower fermentative temperatures which caused that a lower number of genotypes were adapted to those conditions. Moreover, in winery $\mathrm{D}$, the use of higher sulphite concentrations could determine the low $\mathrm{LAB}$ populations found during AF, so quantifying the ID of O. oeni was not possible at this fermentative period.

Table 4 includes the information about the twenty-eight O. oeni genotypes and their frequency (\%) of appearance in each winery. Most of the genotypes (eighteen) appeared only at one stage during the vinification with frequencies from $1 \%$ to $15 \%$, while the rest of genotypes (ten) were isolated at more than one stage, representing highly variable frequencies of appearance from $3 \%$ to $55 \%$. Only three patterns (genotypes 10,11, and 24) were isolated at both AF and MLF.

The frequency of participation of each genotype varied from winery to winery, so dominant ones in one cellar were minority or not present at other one. Thus, genotype 3 was detected in wineries A and C; genotypes 11 and 12 were isolated in wineries $B$ and $C$, while the pattern 10 was identified in three wineries $(\mathrm{A}, \mathrm{B}$, and $\mathrm{C})$ that were further away (Figure 1). However, their frequency of appearance was extremely variable at each winery. Thus, for example, genotype 12 reached the $45 \%$ of the total O. oeni isolates in cellar C, it was the $9 \%$ in B and not being isolated in the other two wineries. This fact proved that although some genotypes appeared in more than one winery, they were not always the majority $O$. oeni strain in spontaneous MLF, because their frequency depended on the elaboration conditions and on the wine composition. Thus, different strains were the best adapted and performed MLF in each winery. On the other hand, the total five genotypes detected in winery $\mathrm{D}$ were not present in the others. It could be related to the different type of winemaking used in this winery (open cement tanks with whole grapes) what might create a special ecosystem with an own microbiota.

Curiously, the two majority genotypes (patterns 10 and 12) found in the wine from cellar $C$ were indistinguishable to the ones detected in the sampled air of the same winery in a study made by Garijo et al. $[38,39]$ at a previous vintage.

Figure 3 shows the distribution of the detected O. oeni genotypes at the analyzed stages in the four wineries. At most stages, in both AF and MLF, mixed O. oeni populations were observed, so there were different genotypes able to share their ecological niche or tank, as other authors have described in MLF $[8,20]$. The number of different identified genotypes at each stage ranged from 0 to 5 and from 2 to 7 during $\mathrm{AF}$ and MLF, respectively. In this study, it was also observed that, between all the genotypes present in the same tank, there 


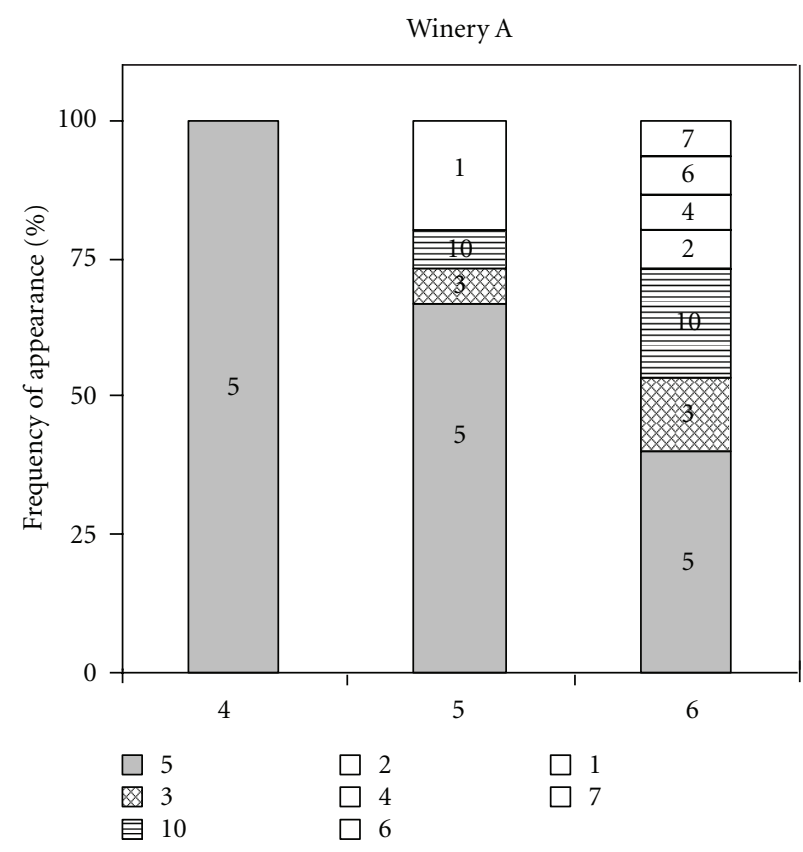

Winery C

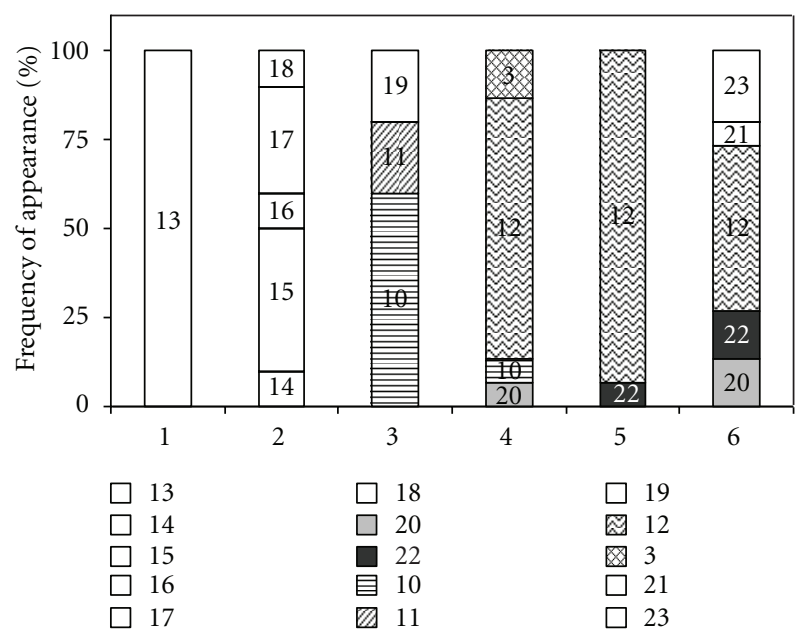

(b)

(a)
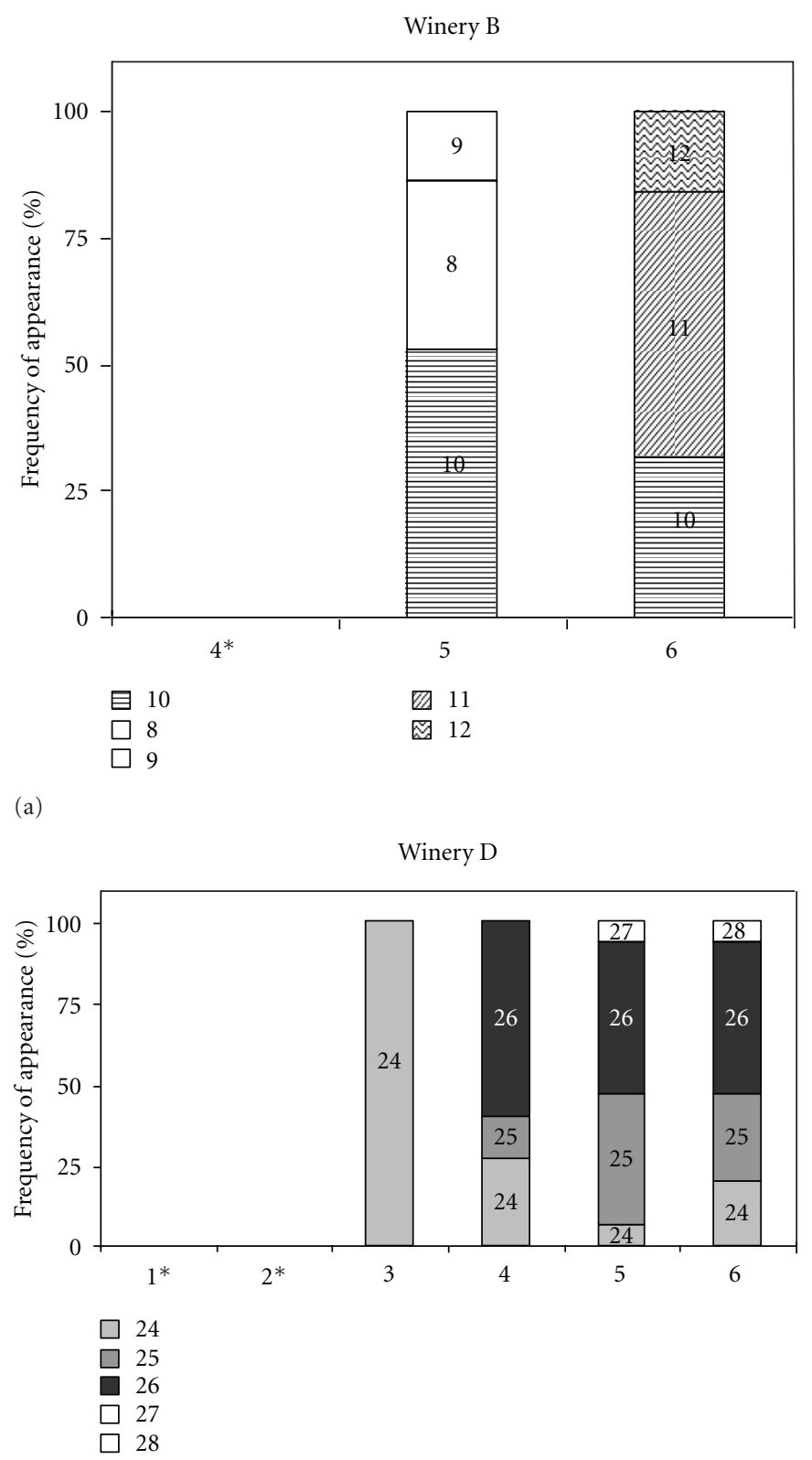

FIGURE 3: Frequency of appearance (\%) of O. oeni genotypes at each sampled stage (1: must; 2: tumultuous AF; 3: final AF; 4: initial MLF; 5: tumultuous MLF; 6: final MLF) in each winery. Empty bars mean genotypes that appeared once, filled bars mean genotypes that appeared in one winery, and textured bars were genotypes detected in more than one winery. ${ }^{*} O$. oeni was not detected.

was at least one detected during all the MLF process and in a bigger percentage, thus it would be the responsible for the MLF. In some cases, this main genotype only appeared in one cellar, such as pattern 5 and 26, but, in others, it was present in more than one winery as patterns 10 and 12 .

In summary, this study is a contribution to a better description of the LAB ecology along the process of Tempranillo wines winemaking. The conditions of elaboration along with the winemaking method influenced the microbial diversity of LAB populations either at species and strain level. $O$. oeni became the main identified species, and a complex diversity of indigenous $O$. oeni strains was observed with genotypes that were relaying each other along the process. This diversity was moderate in MLF so one or two patterns became majority. Genotypes at each winery sometimes were distinctive at each one, and others were coincident between wineries. The four genotypes that were isolated in more than one winery in highly variable frequency could be the result of a successful adaptation to each particular winemaking condition. Convergence in winemaking ecology, due perhaps to the adaptation of strains to the stressful conditions in wine fermentation or perhaps to dispersion factors, such the air, birds, or insects [40], might explain the presence of these four indistinguishable genotypes in wineries that were far apart 
and in the air of one of these cellars. Dominant genotypes (except pattern 5) can be considered as interesting O. oeni strains to be included in a selection process, and they would contribute to preserve the biodiversity and peculiarity of the wine. The aminobiogenic capacity of LAB strains used as starter cultures for MLF should be tested prior to strain selection; thus pattern 5 would result a problematic strain because it persisted as majority in MLF of a wine with a high histamine level. Further investigation must be expanded to more wineries and vintages, including vineyards in order to clarify the aspects that have shaped ecology of the wine LAB in this region.

\section{Acknowledgments}

This work was supported by funding and predoctoral grant (B.O.R., March 6, 2009) of the Government of La Rioja, the I.N.I.A. project RTA2007-00104-00-00, and FEDER of the European Community and was made possible by the collaborating wineries.

\section{References}

[1] J.A. Suárez and B. Íñigo, Microbiología Enológica: Fundamentos de Vinificación, Mundi Prensa, Madrid, Spain, 3rd edition, 2004.

[2] M. Salema, J. S. Lolkema, M. V. San Romão, and M. C. Loureiro Dias, "The proton motive force generated in Leuconostoc oenos by L-malate fermentation," Journal of Bacteriology, vol. 178, no. 11, pp. 3127-3132, 1996.

[3] C. R. Davis, D. J. Wibowo, T. H. Lee, and G. H. Fleet, "Growth and metabolism of lactic acid bacteria during and after malolactic fermentation of wines at different $\mathrm{pH}$," Applied and Environmental Microbiology, vol. 51, no. 3, pp. 539-545, 1986.

[4] M. Dols-Lafargue, E. Gindreau, C. Le Marrec, G. Chambat, A. Heyraud, and A. Lonvaud-Funel, "Changes in red wine soluble polysaccharide composition induced by malolactic fermentation," Journal of Agricultural and Food Chemistry, vol. 55, no. 23, pp. 9592-9599, 2007.

[5] M. A. Pozo-Bayón, E. G. Alegría, M. C. Polo et al., "Wine volatile and amino acid composition after malolactic fermentation: effect of Oenococcus oeni and Lactobacillus plantarum starter cultures," Journal of Agricultural and Food Chemistry, vol. 53, no. 22, pp. 8729-8735, 2005.

[6] J. Guzzo, M. P. Jobin, F. Delmas et al., "Regulation of stress response in Oenococcus oeni as a function of environmental changes and growth phase," International Journal of Food Microbiology, vol. 55, no. 1-3, pp. 27-31, 2000.

[7] J. Guzzo, F. Coucheney, F. Pierre et al., "Acidophilic behaviour of the malolactic bacterium Oenococcus oeni," Sciences des Aliments, vol. 22, no. 1-2, pp. 107-111, 2002.

[8] I. López, C. Tenorio, M. Zarazaga, M. Dizy, C. Torres, and F. Ruiz-Larrea, "Evidence of mixed wild populations of Oenococcus oeni strains during wine spontaneous malolactic fermentations," European Food Research and Technology, vol. 226, no. 1-2, pp. 215-223, 2007.

[9] L. Solieri, F. Genova, M. De Paola, and P. Giudici, "Characterization and technological properties of Oenococcus oeni strains from wine spontaneous malolactic fermentations: a framework for selection of new starter cultures," Journal of Applied Microbiology, vol. 108, no. 1, pp. 285-298, 2010.
[10] E. J. Bartowsky and P. A. Henschke, "The 'buttery' attribute of wine-diacetyl—desirability, spoilage and beyond," International Journal of Food Microbiology, vol. 96, no. 3, pp. 235252, 2004.

[11] A. Marcobal, P. J. Martin-Alvarez, M. C. Polo, R. Munoz, and M. V. Moreno-Arribas, "Formation of biogenic amines throughout the industrial manufacture of red wine," Journal of Food Protection, vol. 69, no. 2, pp. 397-404, 2006.

[12] R. López, I. López-Alfaro, A. R. Gutiérrez et al., "Malolactic fermentation of Tempranillo wine: contribution of the lactic acid bacteria inoculation to sensory quality and chemical composition," International Journal of Food Science and Technology, vol. 46, no. 11, pp. 2373-2381, 2011.

[13] S. Guerrini, A. Bastianini, G. Blaiotta et al., "Phenotypic and genotypic characterization of Oenococcus oeni strains isolated from Italian wines," International Journal of Food Microbiology, vol. 83, no. 1, pp. 1-14, 2003.

[14] I. Andorrà, S. Landi, A. Mas, B. Esteve-Zarzoso, and J. M. Guillamón, "Effect of fermentation temperature on microbial population evolution using culture-independent and dependent techniques," Food Research International, vol. 43, no. 3, pp. 773-779, 2010.

[15] C. Reguant, R. Carreté, M. Constantí, and A. Bordons, "Population dynamics of Oenococcus oeni strains in a new winery and the effect of $\mathrm{SO}_{2}$ and yeast strain," FEMS Microbiology Letters, vol. 246, no. 1, pp. 111-117, 2005.

[16] F. Coucheney, N. Desroche, M. Bou, R. Tourdot-Maréchal, L. Dulau, and J. Guzzo, "A new approach for selection of Oenococcus oeni strains in order to produce malolactic starters," International Journal of Food Microbiology, vol. 105, no. 3, pp. 463-470, 2005.

[17] P. M. Izquierdo, E. García, J. Martínez, and J. L. Chacón, “Selection of lactic bacteria to induce malolactic fermentation in red wine of cv. Cencibel," Vitis, vol. 43, no. 3, pp. 149-153, 2004.

[18] P. Ruiz, P. M. Izquierdo, S. Seseña, and M. L. Palop, "Selection of autochthonous Oenococcus oeni strains according to their oenological properties and vinification results," International Journal of Food Microbiology, vol. 137, no. 2-3, pp. 230-235, 2010.

[19] V. Renouf, O. Claisse, and A. Lonvaud-Funel, "Inventory and monitoring of wine microbial consortia," Applied Microbiology and Biotechnology, vol. 75, no. 1, pp. 149-164, 2007.

[20] P. Ruiz, P. M. Izquierdo, S. Seseña, and M. L. Palop, "Intraspecific genetic diversity of lactic acid bacteria from malolactic fermentation of Cencibel wines as derived from combined analysis of RAPD-PCR and PFGE patterns," Food Microbiology, vol. 25, no. 7, pp. 942-948, 2008.

[21] European Community, "Community methods for the analysis of wine," Commission Regulation 26/76/90, 1990.

[22] R. López, P. Santamaría, and A. R. Gutiérrez, Aspectos Prácticos de la Fermentación Maloláctica en Vinos Tintos, Editorial Académica Española, Madrid, Spain, 1st edition, 2011.

[23] J. G. Holt, N. R. Krieg, P. H. A. Sneath, J. Y. Staley, and S. T. Williams, Bergey's Manual of Determinative Bacteriology, Hensyl WR, Baltimore, Md, USA, 9th edition, 1994.

[24] L. Beneduce, G. Spano, A. Vernile, D. Tarantino, and S. Massa, "Molecular characterization of lactic acid populations associated with wine spoilage," Journal of Basic Microbiology, vol. 44, no. 1, pp. 10-16, 2004.

[25] G. Zapparoli, S. Torriani, P. Pesente, and F. Dellaglio, “Design and evaluation of malolactic enzyme gene targeted primers for 
rapid identification and detection of Oenococcus oeni in wine," Letters in Applied Microbiology, vol. 27, no. 5, pp. 243-246, 1998.

[26] I. Lopez, F. Ruiz-Larrea, L. Cocolin et al., "Design and evaluation of PCR primers for analysis of bacterial populations in wine by denaturing gradient gel electrophoresis," Applied and Environmental Microbiology, vol. 69, no. 11, pp. 6801-6807, 2003.

[27] S. F. Altschul, W. Gish, W. Miller, E. W. Myers, and D. J. Lipman, "Basic local alignment search tool," Journal of Molecular Biology, vol. 215, no. 3, pp. 403-410, 1990.

[28] B. Birren and E. Lai, Pulsed Field Gel Electrophoresis: A Practical Guide, Academic Press, San Diego, Calif, USA, 1st edition, 1993.

[29] M. Larisika, H. Claus, and H. König, "Pulsed-field gel electrophoresis for the discrimination of Oenococcus oeni isolates from different wine-growing regions in Germany," International Journal of Food Microbiology, vol. 123, no. 1-2, pp. 171176, 2008.

[30] A. Lonvaud-Funel, "Biogenic amines in wines: role of lactic acid bacteria," FEMS Microbiology Letters, vol. 199, no. 1, pp. 9-13, 2001.

[31] J. M. Landete, B. De Las Rivas, A. Marcobal, and R. Muñoz, "PCR methods for the detection of biogenic amine-producing bacteria on wine," Annals of Microbiology, vol. 61, no. 1, pp. 159-166, 2011.

[32] R. Guzzon, E. Poznanski, L. Conterno, P. Vagnoli, S. KriegerWeber, and A. Cavazza, "Selection of a new highly resistant strain for malolactic fermentation under difficult conditions," South African Journal of Enology and Viticulture, vol. 30, no. 2, pp. 133-141, 2009.

[33] C. Reguant, R. Carreté, N. Ferrer, and A. Bordons, "Molecular analysis of Oenococcus oeni population dynamics and the effect of aeration and temperature during alcoholic fermentation on malolactic fermentation," International Journal of Food Science and Technology, vol. 40, no. 4, pp. 451-459, 2005.

[34] P. M. I. Cañas, P. R. Pérez, S. S. Prieto, and M. L. P. Herreros, "Ecological study of lactic acid microbiota isolated from Tempranillo wines of Castilla-La Mancha," Journal of Bioscience and Bioengineering, vol. 108, no. 3, pp. 220-224, 2009.

[35] B. Rojo-Bezares, Y. Sáenz, L. Navarro, M. Zarazaga, F. Ruiz-Larrea, and C. Torres, "Coculture-inducible bacteriocin activity of Lactobacillus plantarum strain J23 isolated from grape must," Food Microbiology, vol. 24, no. 5, pp. 482-491, 2007.

[36] F. Bert, C. Branger, and N. Lambert-Zechovsky, "Pulsed-field gel electrophoresis is more discriminating than multilocus enzyme electrophoresis and random amplified polymorphic DNA analysis for typing pyogenic streptococci," Current Microbiology, vol. 34, no. 4, pp. 226-229, 1997.

[37] P. Santamaría Aquilúe, Ecología de la Fermentación Alcohólica en la D.O.C.A. Rioja: Selección de Levaduras para la Elaboración de Vinos Tintos, University of La Rioja, La Rioja, Spain, 2009.

[38] P. Garijo, R. López, P. Santamaría et al., "Presence of enological microorganisms in the grapes and the air of a vineyard during the ripening period," European Food Research and Technology, vol. 233, no. 2, pp. 359-365, 2011.

[39] P. Garijo, R. López, P. Santamaría et al., "Presence of lactic bacteria in the air of a winery during the vinification period," International Journal of Food Microbiology, vol. 136, no. 1, pp. 142-146, 2009.

[40] N. Francesca, M. Chiurazzi, R. Romano, M. Aponte, L. Settanni, and G. Moschetti, "Indigenous yeast communities in the environment of "Rovello bianco" grape variety and their use in commercial white wine fermentation," World Journal of Microbiology and Biotechnology, vol. 26, no. 2, pp. 337-351, 2010. 

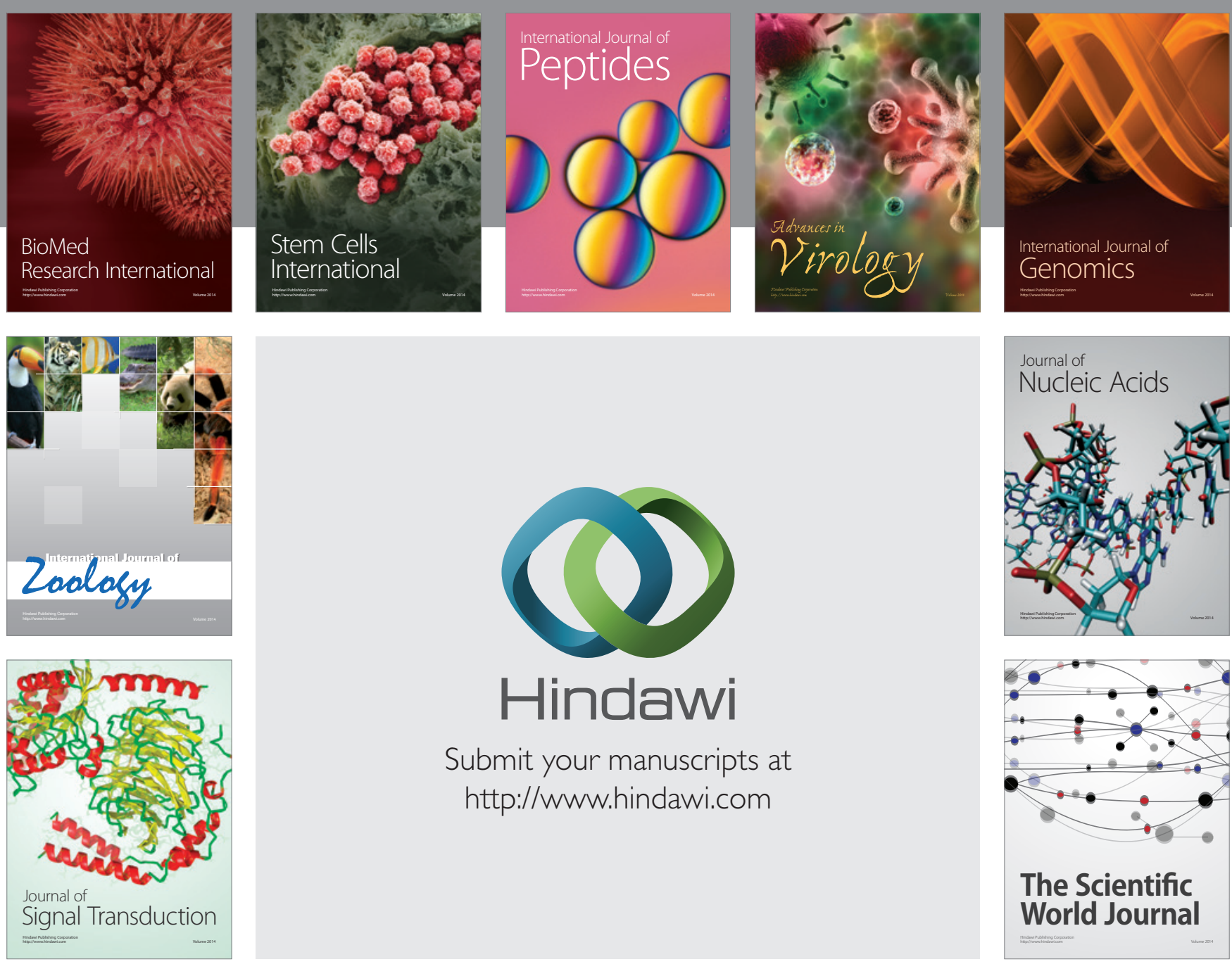

Submit your manuscripts at

http://www.hindawi.com
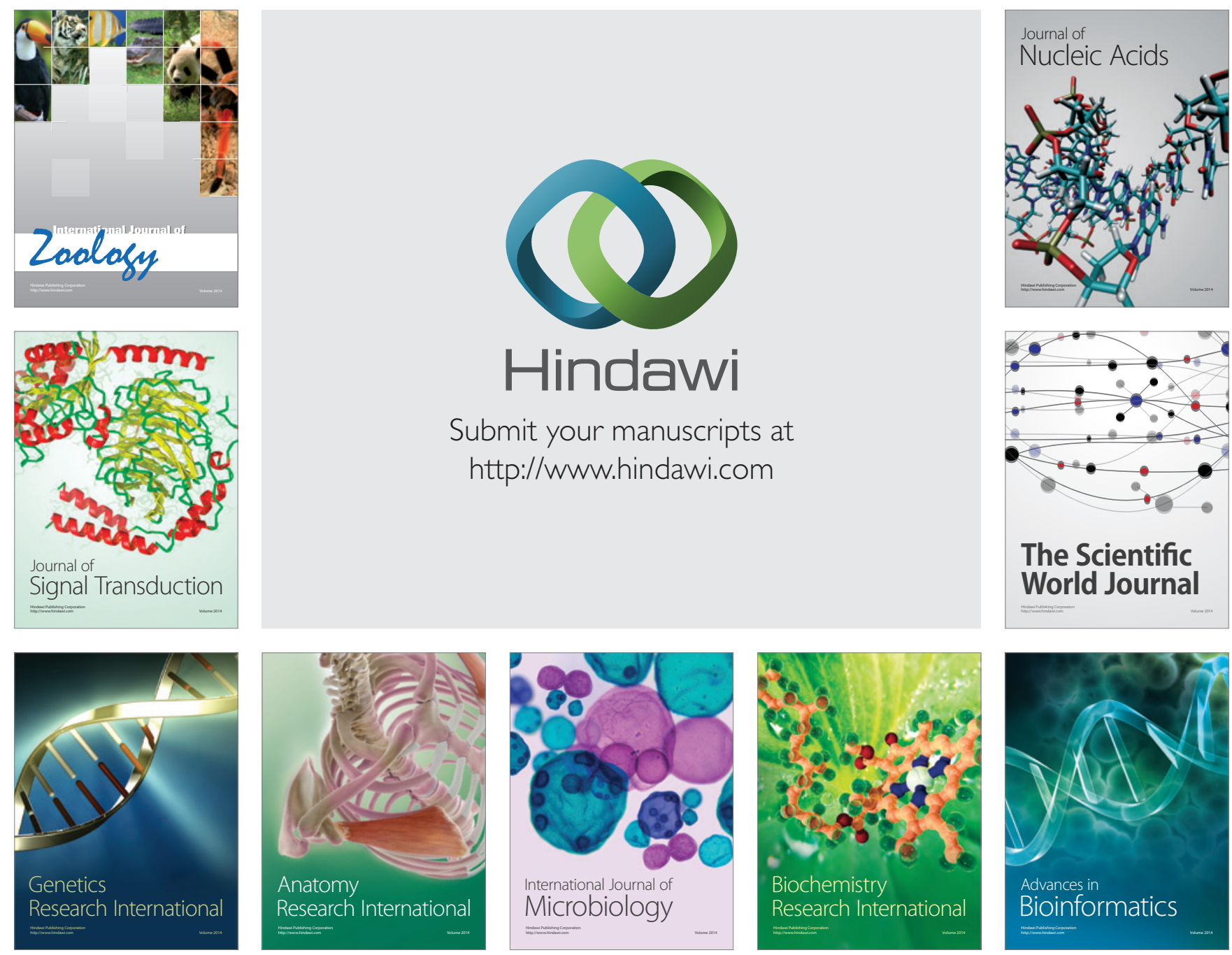

The Scientific World Journal
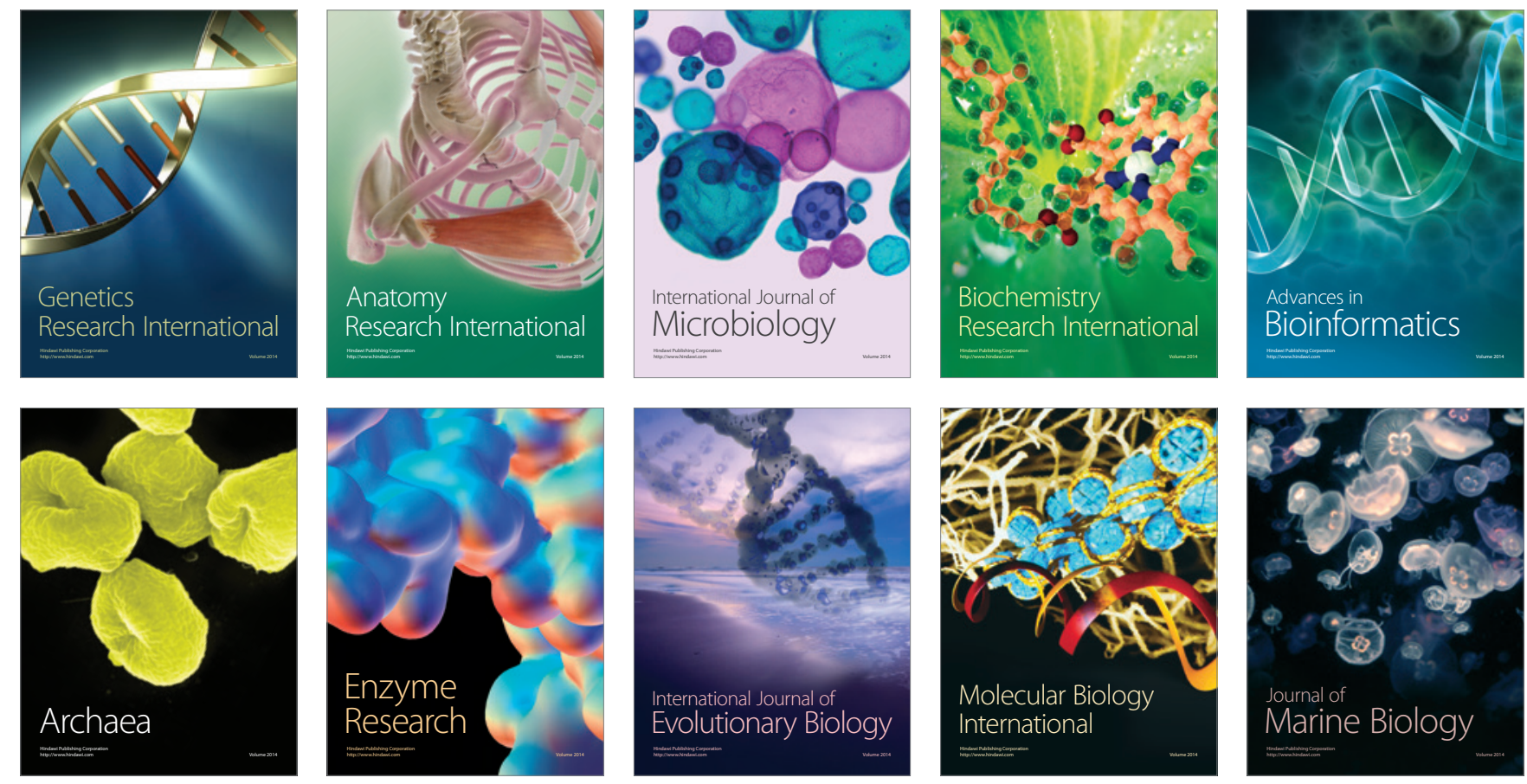